\title{
Assessment of DNA methylation status in early stages of breast cancer development
}

\author{
A Q van Hoesel ${ }^{1}$, Y Sato ${ }^{1}$, D A Elashoff ${ }^{2}$, R R Turner ${ }^{3}$, A E Giuliano ${ }^{4}$, J M Shamonki ${ }^{3}$, P J K Kuppen ${ }^{5}$, \\ C J H van de Velde ${ }^{5}$ and D S B Hoon ${ }^{\star 1}$ \\ ${ }^{1}$ Department of Molecular Oncology, John Wayne Cancer Institute, 2200 Santa Monica Blvd, Santa Monica, CA 90404, USA; \\ ${ }^{2}$ Department of Medicine, Statistics Core, University of California Los Angeles, West Los Angeles, Los Angeles, CA 90095, USA; \\ ${ }^{3}$ Department of Pathology, Santa Monica, CA 90404, USA; ${ }^{4}$ The Margie Robert Petersen Breast Center, St. John's Health Center, \\ 2200 Santa Monica Blvd, Santa Monica, CA 90404, USA and ${ }^{5}$ Department of Surgery, Leiden University Medical Center, \\ Albinusdreef 2, 2333ZA Leiden, The Netherlands
}

Background: Molecular pathways determining the malignant potential of premalignant breast lesions remain unknown. In this study, alterations in DNA methylation levels were monitored during benign, premalignant and malignant stages of ductal breast cancer development.

Methods: To study epigenetic events during breast cancer development, four genomic biomarkers (Methylated-IN-Tumour (MINT)17, MINT31, RARß2 and RASSF1A) shown to represent DNA hypermethylation in tumours were selected. Laser capture microdissection was employed to isolate DNA from breast lesions, including normal breast epithelia $(n=52)$, ductal hyperplasia $(n=23)$, atypical ductal hyperplasia $(n=31)$, ductal carcinoma in situ (DCIS, $n=95)$ and AJCC stage I invasive ductal carcinoma (IDC, $n=34$ ). Methylation Index (MI) for each biomarker was calculated based on methylated and unmethylated copy numbers measured by Absolute Quantitative Assessment Of Methylated Alleles (AQAMA). Trends in MI by developmental stage were analysed.

Results: Methylation levels increased significantly during the progressive stages of breast cancer development; $P$-values are $0.0012,0.0003,0.012,<0.0001$ and $<0.0001$ for MINT17, MINT31, RAR $\beta 2$, RASSF1A and combined biomarkers, respectively. In both DCIS and IDC, hypermethylation was associated with unfavourable characteristics.

Conclusion: DNA hypermethylation of selected biomarkers occurs early in breast cancer development, and may present a predictor of malignant potential.

Invasive ductal breast tumours are thought to arise from benign breast tissues through multiple transforming events over time (Wellings and Jensen, 1973; Wellings et al, 1975; Jensen et al, 1976; Allred and Mohsin, 2000). Models of breast cancer development have identified several histologically recognisable breast lesions as potentially precancerous. Ductal hyperplasia $(\mathrm{DH})$, atypical ductal hyperplasia $(\mathrm{ADH})$ and ductal carcinoma in situ (DCIS) are associated with a 1.5, 5 and 10-fold increased relative risk for future invasive ductal cancer (IDC), respectively (Dupont and Page, 1985; Page et al, 1985; Dupont et al, 1993; Page et al, 1995; Hartmann et al, 2005; Degnim et al, 2007). Although such lesions signify an increased risk for the development of invasive breast cancer, not all patients will indeed acquire invasive disease. The majority of proliferative lesions does not have the molecular characteristics that enable them to progress to invasiveness. Factors determining the behaviour of proliferative lesions remain unknown. Tools for risk stratification are warranted to identify patients diagnosed with proliferative lesions of the breast who may benefit from surgical treatment or adjuvant therapy, vs patients who may safely refrain from treatment. Moreover, identification of key changes in proliferative lesions is relevant as it may render targets for novel preventative therapies. Detection and intervention during early 
stages of breast cancer development offers an opportunity to decrease the incidence of invasive breast cancer and to improve the survival of women at risk of developing breast cancer.

DNA hypermethylation is recognised as an important epigenetic aberrancy contributing to the development of several types of cancer (Esteller, 2008), including breast cancer (Lo and Sukumar, 2008). In this study, methylation levels were assessed during key steps in breast cancer development, including transitions from $\mathrm{DH}$ to $\mathrm{ADH}$ to DCIS. Four candidate methylation biomarkers known to be aberrantly hypermethylated in invasive breast cancer were selected. $\operatorname{RAR} \beta 2$ and RASSF1A are tumour suppressor genes, whose loss of expression in invasive breast tumours is known to be partially attributable to promoter hypermethylation (Sirchia et al, 2000; Agathanggelou et al, 2005; Shinozaki et al, 2005; Dumont et al, 2009; Van der Auwera et al, 2010). MINT17 and MINT31 belong to the group of Methylated-IN-Tumour (MINT) loci, and are biomarkers with known cancer-associated methylation in gastro-intestinal tumours (Toyota et al, 1999; de Maat et al, 2007), melanoma (Tanemura et al, 2009) and breast cancer (Roll et al, 2008; van Hoesel et al, 2012). This study explores the association of aberrant methylation of these four markers with malignant transformation. In DCIS and IDC, we also assessed the relation of aberrant methylation and established predictors in breast cancer, such as oestrogen receptor (ER), progesterone receptor (PR), HER2 and histological grade (Allred et al, 2009; Rakovitch et al, 2012).

Lesion size has presented an obstacle for detailed molecular studies on archival paraffin-embedded tissue specimens of proliferative breast lesions. In this study, laser capture microdissection (LCM) and in situ bisulfite modification were employed for methylation analysis by PCR, enabling assessment of small lesions $(<1.5 \mathrm{~mm})$. This study aimed to characterise epigenetic biomarkers associated with progression in premalignant breast lesions towards the malignant phenotype.

\section{MATERIALS AND METHODS}

Clinical Specimens. Female patients who underwent a resection biopsy of the breast and were subsequently diagnosed with ductal proliferative disease at the Department of Pathology at St. Johns Health Center between 1996 and 2008 were identified. Patients with mixed lobular and ductal lesions, or with insufficient amounts of archived formalin-fixed paraffin-embedded (FFPE) tissues were excluded. Archived FFPE tissues were obtained from a total of 235 lesions, derived from 138 patients. Selected tissues comprised normal breast tissues $(n=52), \mathrm{DH}(n=23), \mathrm{ADH}(n=31)$, DCIS $(n=95)$ and AJCC stage I IDC $(n=34)$. Ductal carcinoma in situ tissues included low-grade $(n=30)$, intermediate-grade $(n=27)$, high-grade $(n=25)$ lesions and lesions of unspecified grade $(n=13)$. The patient cohort contained both patients diagnosed

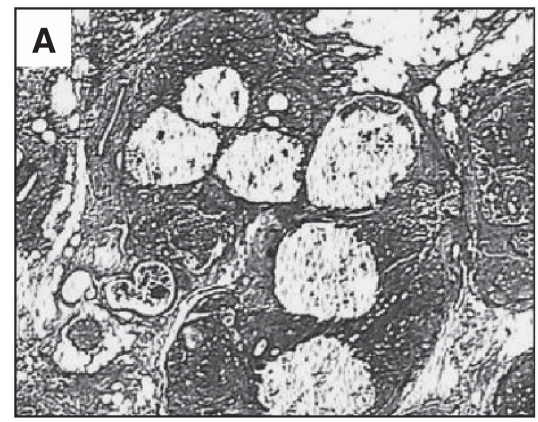

with isolated lesions, as well as patients diagnosed with (multiple) synchronous lesions. Two expert pathologists (RRT and JMS) reviewed the H\&E slide for each selected tissue specimen to identify and mark proliferative lesions and normal epithelia (Figure 1).

Use of selected tissues for methylation studies was approved by the Western Institutional Review Board (Olympia, Washington).

DNA preparation from normal and (Pre)malignant breast Tissues. Laser capture microdissection was employed to harvest DNA from normal breast epithelia and proliferative ductal breast lesions. CapSure Macro LCM caps (MDS Analytical Technologies, Sunnyvale, CA, USA) were used to capture dissected tissues. Deparaffinized tissue sections of $8 \mu \mathrm{m}$ thickness on non-adhesive glass slides were used as a tissue source. To determine the required surface area, a test was undertaken measuring copy numbers in incremental surface areas, ranging from $10^{5}$ to $10^{7} \mu \mathrm{m}^{2}$. Lesion surface area for LCM capturing was determined at $>1 \mathrm{~mm}^{2}$. For each specimen, the original H\&E slide marked by the pathologists served as roadmap for the accurate isolation of separate tissues of interest.

Laser capture microdissection tissues were subjected to on-cap in situ sodium bisulfite modification to enable assessment of DNA methylation levels (Sunami E et al, 2011). To denature sample DNA in preparation for sodium bisulfite modification, on-cap tissues were incubated in $0.2 \mathrm{M} \mathrm{NaOH}$ at $37^{\circ} \mathrm{C}$ for $15 \mathrm{~min}$. Next, captured tissues were incubated in sodium bisulfite solution at $60^{\circ} \mathrm{C}$ for $8 \mathrm{~h}$, rinsed with molecular grade water twice for desalting and incubated in $0.3 \mathrm{M}$ $\mathrm{NaOH}$ at $37^{\circ} \mathrm{C}$ for $15 \mathrm{~min}$ to finalise bisulfite modification. Bisulfite-modified DNA of on-cap tissues was brought into solution by digesting on-cap tissues in lysis buffer containing proteinase $\mathrm{K}$ (Sigma, St. Louis, MO, USA) overnight at $50^{\circ} \mathrm{C}$. Finally, the proteinase $\mathrm{K}$ enzyme was deactivated at $95^{\circ} \mathrm{C}$ for $15 \mathrm{~min}$.

Quantitative PCR to assess methylation levels. Methylation levels for all four genomic loci were measured by Absolute Quantitative Assessment of Methylated Alleles (AQAMA) PCR, as published previously (de Maat et al, 2007; Tanemura et al, 2009). In short, a universal set of primer was designed for each biomarker, annealing to both methylated and unmethylated bisulfite-modified DNA sequences. A pair of minor groove-binding probes was designed to specifically report amplification of methylated and unmethylated sequences. Primer and probe sequences were as follows: MINT17, 5'-AGGGGTTAGGTTGAGGTTGTT-3' (forward), 5'-TCTACCTCTTCCCAAATTCCA-3' (reverse), 5'-TTG GATGGATCGCGG-3' (methylated sequence-specific (M) probe), $5^{\prime}$-TATTTTGGATGGATTGTGG-3' (unmethylated sequencespecific (U) probe); MINT31, 5'-TAAAGTGAGGGGTGGTGA TG-3' (forward), 5'-AAAAACACTTCCCCAACATCT-3' (reverse), 5'-AGGTTTCGTCGTGTTT-3' (M probe), 5'-AGGTTTTGTTGT GTTTAT-3' (U probe); RASSF1A, 5'-AAGGAGGGAAGGAAGGG

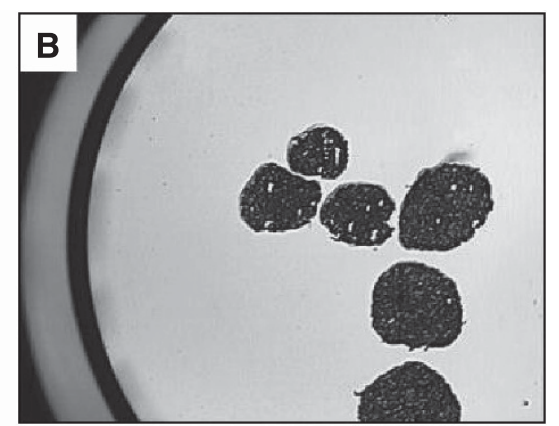

Figure 1. Laser capture microdissection of ductal carcinoma in situ. All tissue types assayed in this study were carefully microdissected by LCM from deparaffinized, hematoxylin-stained slide sections of $\sim 8 \mu \mathrm{m}$ thickness. A representative slide example of capturing DCIS tissue is shown after LCM in (A), and the microdissected tissues LCM on-cap in (B). 
TAAG-3' (forward), 5'-CTCCCCCAAAATCCAAACTAA-3' (reverse), 5'-TTTGCGAGAGCGCGT-3' (M probe), 5' ${ }^{\prime}$-TTTGTG AGAGTGTGTTTAG-3' (U probe), and RARß2, $5^{\prime}$-AGTTGTTTGAGGATTGGGATGT-3' (forward), $5^{\prime}$-ATCCCAAATTCTCCTT CCAAATA-3' (reverse), 5'-AGAACGCGAGCGATT-3' (M probe) and $5^{\prime}$-AGAATGTGAGTGATTTGAG-3' (U probe). Copy numbers of methylated and unmethylated sequences were quantified based on a separate plasmid standard curve for each. A total PCR reaction volume of $10 \mu \mathrm{l}$ was used, containing $2 \mu \mathrm{l}$ of tissue lysate, $350 \mu \mathrm{mol}$ of dNTP, 1.4 units Accustart DNA polymerase (QuantaBiosciences, Gaithersburg, MD, USA), $5 \mathrm{mmol} \mathrm{MgCl}$, $0.4 \mu \mathrm{mol}$ of forward and reverse primer, $0.025 \mathrm{pmol}$ of each probe and ROX for passive reference fluorescence. All sample reactions were performed as triplicates. Controls included universal methylated and universal unmethylated controls as previously published (Tanemura et al, 2009), and zero-template controls. Performance and accuracy of the methodology used in this study has been previously demonstrated (de Maat et al, 2007).

Statistical analysis. Methylation levels were expressed as Methylation Index (MI), calculated from absolute copy numbers as follows: $\quad \mathrm{MI}=$ methylated copy number/(methylated copy number + unmethylated copy number). The MI is a continuous value ranging from 0 to 1 , and can be interpreted as methylation percentage, with $\mathrm{MI}=0$ representing complete absence of methylation and $\mathrm{MI}=1$ meaning complete methylation. Methylation Index was obtained for each sample, and mean MI was calculated for each tissue category. In addition, a standardized average $\mathrm{MI}\left(\mathrm{MI}^{\mathrm{panel}}\right)$ was calculated to assess alterations in methylation of the four biomarkers together. Both single biomarker $\mathrm{MI}$ and $\mathrm{MI}^{\text {panel }}$ were used for statistical analysis. For all statistical tests, $P$-values $<0.05$ were considered significant. Pearson's correlation coefficient was used to examine the linearity between incremental LCM surface areas and DNA copy numbers for determining the required surface area. Association between MI and tumour characteristics, such as ER, PR, HER2 and grade, was examined using the $\chi^{2}$ test. Trends in MI during breast cancer development were analysed using both a categorical mixed-effects model, considering the included tissue types as independent entities, and a linear mixed-effects model, considering the tissue types as related progressive steps (Beitler and Landis, 1985; Roy, 2009; Bastogne et al, 2010). Congruence between histological grade of DCIS and synchronous invasive carcinoma was assessed by the Fisher's exact test.

\section{RESULTS}

Linearity of LCM surface area and copy numbers. At first, a LCM test study was undertaken to determine the required tissue surface area for capturing by LCM to reliably perform the AQAMA assay, yielding approximately $>10^{2}$ copy numbers upon amplification. A series of homogenous breast tissue was captured with incremental surface areas, ranging from $10^{5}$ to $10^{7} \mu \mathrm{m}^{2}$ of captured tissue. Samples were processed and used for AQAMA PCR as described above. Copy numbers were calculated for each surface area. Pearson's correlation coefficients for linearity between captured surface area and total copy numbers was 0.97 $(P=0.002)$ (Figure 2). A captured tissue surface area of $10^{6} \mu \mathrm{m}^{2}$ sufficed to achieve $>10^{2}$ copy numbers, and was used for the rest of the study.

Methylation levels during Breast Cancer Development. AQAMA PCR was successful in 228 (97\%), 220 (94\%), 225 (96\%) and 199 (85\%) of 235 lesions for MINT17, MINT31, RAR $\beta 2$ and RASSF1A, respectively. Methylation Index of MINT17 was $0.16,0.16,0.24,0.26$ and 0.30 for normal breast epithelia, $\mathrm{DH}$, $\mathrm{ADH}, \mathrm{DCIS}$ and IDC, with increased methylation occurring in the

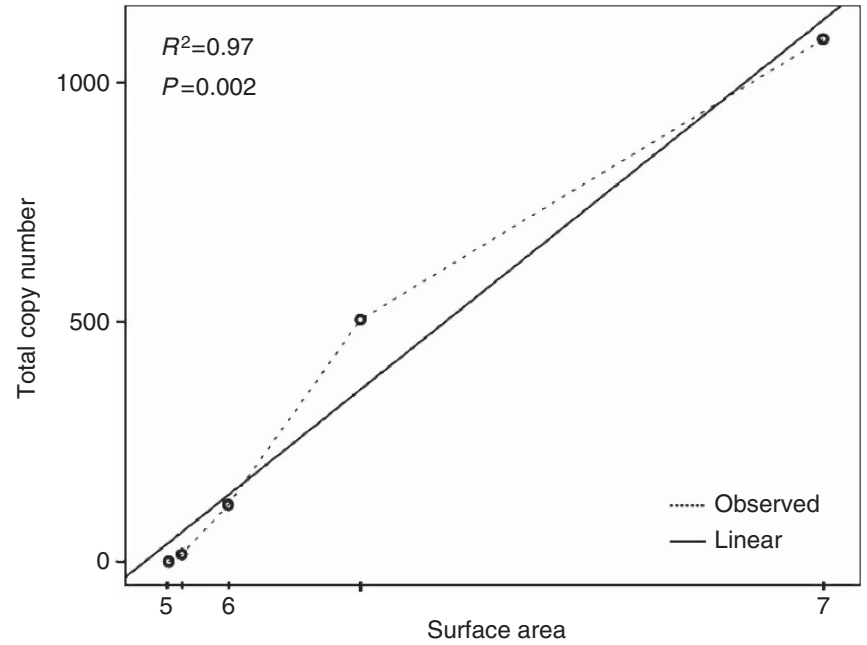

Figure 2. Linearity of LCM surface area and total copy numbers. A series of incremental surface areas of $10^{5}, 3 \times 10^{5}, 10^{6}, 3 \times 10^{6}$ and $10^{7} \mu \mathrm{m}^{2}$ was captured. Tissues were subjected to in situ on-cap bisulfite modification followed by proteinase $K$ treatment. Tissue lysate was used for AQAMA PCR for copy number measurement. Data of MINT17 copy numbers are shown. The Pearson $R^{2}$ was 0.97 for correlation between increasing copy numbers with increasing surface area $(P=0.002)$. $X$-axis indicates the respective surface areas assayed; the numbers represent captured $\mu \mathrm{m}$ in multiples of ten. This figure also demonstrates adequate PCR efficiency for captured and processed sample DNA, yielding an efficient amplification slope (Pearson $R^{2}$ 0.97) in a serial dilution series.

development from $\mathrm{DH}$ to $\mathrm{ADH}$ ( $P=0.001$ for linear trend). Likewise, RARbeta MI increased most during transition from $\mathrm{DH}$ to $\mathrm{ADH}$, with methylation levels $0.16,0.16,0.29,0.28$ and 0.22 in successive tissue types (linear trend $P=0.01$ ). RASSF1A MI marked the transition from normal to DH (MI 0.39, 0.75, 0.67, 0.79 and 0.76 , linear trend $P<0.001$ ). MINT31 showed increasing levels of methylation throughout development, but a decrease from DCIS towards IDC (MI 0.05, 0.02, 0.10, 0.21 and 0.13 for normal breast epithelia, $\mathrm{DH}, \mathrm{ADH}, \mathrm{DCIS}$ and IDC, respectively, linear trend $P=0.003$ ).

Mixed-effects model analysis of MI $v s$ breast cancer development stage showed a significant trend for increasing levels of methylation of all four biomarkers during progression from benign towards malignant $(P<0.001$ for trend by both categorical and linear mixed-effects model) (Figure 3). Methylation of all four biomarkers combined $\left(\mathrm{MI}^{\text {panel}}\right)$ for normal breast epithelia, $\mathrm{DH}, \mathrm{ADH}, \mathrm{DCIS}$ and IDC was $0.17,0.28,0.33,0.38$ and 0.35 , respectively.

Relationship between methylation levels and histological grade of DCIS and invasive carcinoma. Of 95 DCIS samples included in this study, 30 were low-grade, 27 were intermediate-grade and 25 were high-grade lesions. The remaining 13 DCIS samples were of unspecified histological grade. Of 34 IDCs, 10 displayed low histological grade, 12 were intermediate grade, seven were high grade and five cases were of unspecified histological grade. In 23 patients with synchronous DCIS and IDC, histological grade was known for both lesions. Histological grade of DCIS was predictive of histological grade of synchronous IDC. Congruence was present in 17 out of 23 lesions $(74 \%)(P<0.001)$. All six intermediate-grade DCIS concurred with intermediate-grade IDC. Of the eight highgrade DCIS, six concurred with high-grade IDC and two with intermediate-grade IDC. Five out of nine low-grade DCIS coexisted with low-grade IDC and four with intermediate-grade IDC. 

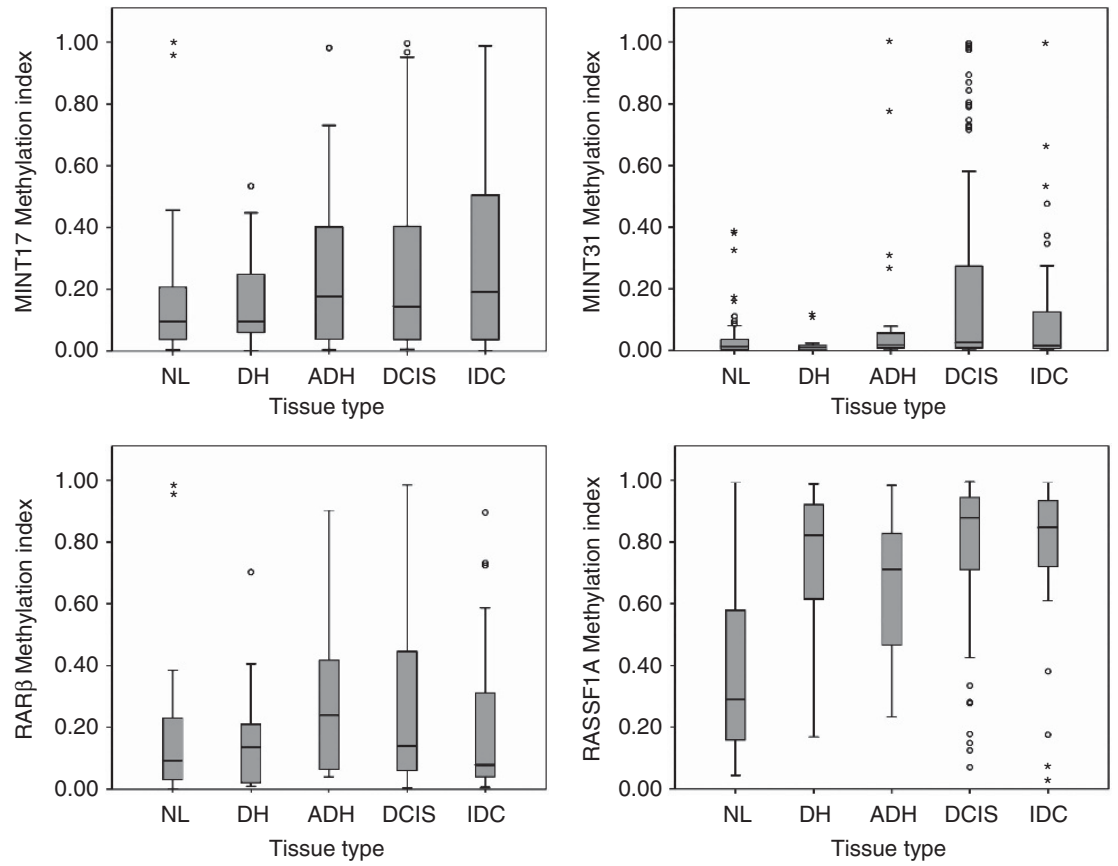

Figure 3. Methylation Index by tissue type. Boxplots showing Methylation Index of MINT17, MINT31, RARß2 and RASSF1A vs tissue type (normal breast epithelia $(\mathrm{NL})$, ductal hyperplasia $(\mathrm{DH})$, atypical ductal hyperplasia $(\mathrm{ADH})$, ductal carcinoma in situ (DCIS) and invasive ductal cancer (IDC)). Boxplots show quartiles, median and outliers.

In DCIS, MI was not predictive of histological grade. Also, no significant difference was found in $\mathrm{MI}^{\text {panel }}$ between low-grade, intermediate-grade and high-grade DCIS. In IDC, a trend was observed towards higher MINT31 MI with higher histological grade, though not significant $(P=0.07)$.

Association between MI and ER, PR and HER2 in DCIS and Invasive Carcinoma. Oestrogen receptor, PR and HER2 were known in 28 of 34 IDC. In DCIS, ER and PR were known in 51 of 95 , and HER2 was available in 29 of 95 DCIS. In DCIS, aberrant MINT31 methylation was associated with ER expression, showing increased MINT31 MI in ER-negative lesions $(P<0.001)$. Increased MI of RAR $\beta 2$ was associated with HER2 amplification in DCIS $(P=0.046)$. Methylation Index ${ }^{\text {panel }}$ was significantly higher in ER-negative DCIS lesions $(P=0.01)$. A trend existed towards increased $\mathrm{MI}^{\text {panel }}$ in PR-negative DCIS $(P=0.11)$ and HER2positive DCIS $(P=0.10)$.

In IDC, MINT31 MI was also increased in ER-negative tumours as compared with ER-positive tumours $(P=0.046)$. In addition, MINT31 MI was higher in tumours with amplification of HER2 $(P=0.014)$.

\section{DISCUSSION}

The introduction of population-wide screening mammography has caused an increase in diagnosis of invasive breast cancer. But more so, it has dramatically increased the diagnosis of clinically occult premalignant breast lesions. In 2008, 67770 new cases of DCIS were diagnosed (Jemal et al, 2008), compared with 4800 cases in 1983 (Ernster et al, 1996). In addition, breast biopsies prompted by abnormal mammographic findings, such as microcalcifications (Murphy and DeSchryver-Kecskemeti, 1978) or soft-tissue densities, frequently reveal benign or other premalignant lesions such as $\mathrm{DH}$ and $\mathrm{ADH}$. This development has prompted the quest to determine clinical importance of these lesion types. It also presents the opportunity for intervention in premalignant stages. Risk assessment for women diagnosed with premalignant lesions has become increasingly important for improved care of patients with disease of the breast.

This study aimed to identify epigenetic characteristics of premalignant lesions that may provide targets for such early intervention. So far, studies into the molecular characteristics of invasive and adjacent premalignant lesions have been undertaken analysis of genomic structural changes, loss of heterozygosity, and gene expression analysis (O'Connell et al, 1998; Buerger et al, 1999; Jeffrey and Pollack, 2003; Ma et al, 2003; Burstein et al, 2004). Fewer studies have looked into methylation aberrancies and the pattern of their occurrence during breast cancer longitudinal progression. Gene methylation governs cell differentiation, and other aberrancies which can be key changes that steer cells towards a malignant phenotype. A study indicating the importance of methylation aberrancies in early malignant transformation showed methylation of p16 to be a key factor in the earliest onset of premalignant programmes, even in normal-appearing epithelial cells (Foster et al, 1998; Crawford et al, 2004). In our study, we have taken a novel approach to illuminating methylation biomarkers in premalignant lesion. Previous reports on methylation patterns in premalignant tissues often used paired tissues, either pairing normal breast tissue with DCIS or invasive breast cancer (Hoque et al, 2009; Muggerud et al, 2010). Few studies have used a 'continuous' model as we have in our current design. Using LCM with on-cap bisulfite modification has made the study of small premalignant lesions feasible. Also, few studies so far have assessed methylation in relation to ER and HER2 status of premalignant lesion, although these are some of the most powerful predictors of invasive potential of DCIS known to date (Meijnen et al, 2008; Roses et al, 2009; Kerlikowske et al, 2010). Finally, most studies focus on individual gene coding biomarkers, whereas we used MINT markers that were previously shown indicative of genome-wide promoter hypermethylation, and as such can be regarded surrogate markers for methylation machinery malfunctioning. This study demonstrates the occurrence of methylation aberrancies during the key developmental steps of ductal breast cancer. Our data show that hypermethylation of MINT17 and RAR $\beta 2$ marks the transition from proliferative epithelial hyperplasia 
towards atypia, occurring especially during transition from $\mathrm{DH}$ to $\mathrm{ADH}$. In our study, RASSF1A hypermethylation was an early marker of proliferative development, signalling the transition from normal epithelia towards DH. A study by Moelans et al (2011) suggest that DCIS is epigenetically as advanced as IDC. This is in concurrence with our results, showing aberrant methylation occurring in developmental stages as early as transition towards atypia or even proliferation. The clinical importance of hormone receptor expression in DCIS is emphasised in recent studies (Allred et al, 2012). Interestingly, we showed that aberrant methylation was associated with unfavourable lesion characteristics in DCIS with known ER, PR and HER2. Hypermethylation of MINT31 was associated with ER negativity in both DCIS and IDC. Methylation Index ${ }^{\text {panel }}$ was also associated with ER negativity in DCIS but not in IDC. Our previous study (van Hoesel et al, 2012) demonstrated association 'Methylation-High' or 'Meth-H' phenotype with ER positivity in IDC. As $\mathrm{MI}^{\text {panel }}$ and Meth-H overlap in included markers (both include MINT17, MINT31 and RARß2), these results seem contradicting. However, our current study included RASSF1A as well. Furthermore, Meth-H was defined as methylation 2 s.d.'s above normal breast tissue levels of three markers in a binary fashion, whereas $\mathrm{MI}^{\text {panel }}$ is a continuous value. Importantly, our current study includes AJCC stage 1 IDC only, whereas our previous study used breast tumour samples of AJCC stages 1-3. Because of these differences, results of both studies do not exclude each other. The association of aberrant methylation and hormone receptor expression in DCIS is novel and warrants exploration of precancer analysis.

Our data illustrate that aberrant methylation is an important event in the development of ductal breast cancer. Methylation markers can be useful tools to stage proliferative lesions. This study provides a first step towards the identification of methylation markers with possible value predicting malignant potential of premalignant breast lesions; it illustrates that studies assessing methylation aberrancies in association with outcome in patients with premalignant lesions are warranted. Methylation aberrancies may provide a therapeutic target in patients with premalignant lesions.

This study shows the applicability of LCM and in situ on-cap bisulfite modification for the exploration of methylation aberrancies in lesions as small as $1 \mathrm{~mm}^{2}$, paving the way for further molecular studies dealing with very small lesions. Few studies have been published using these combined techniques. Studies previously published use pre-amplification steps to yield results, possibly introducing bias. Dietrich et al (2009) report preamplification while successfully retaining information on DNA methylation, thus avoiding such bias. However, the method presented in our studies makes extra amplification steps unnecessary, provided that tissue size exceeds $1 \mathrm{~mm}^{2}$. The development of a method that saves processing steps may be valuable, as studies warranting LCM are tedious time consuming, making them less easily adaptable to clinical-pathology settings followed by small amounts of DNA extraction. The lesions size did pose a limit to the number of biomarkers that could be assessed, limiting our study to four biomarkers with techniques available. Also, our method was not suitable for very small lesions, because total tissue size needed was $1 \mathrm{~mm}^{2}$ (for small lesions, we used multiple tissues slides).

While radiographical detection of premalignant lesions offers a great opportunity to interfere with breast cancer development at an early stage, strategies to translate this opportunity into therapy are still waiting to be developed. Importantly, not all premalignant lesions progress into cancer. To this end, tools need to be identified for risk stratification of premalignant lesions. Epigenetic aberrancies occur frequently in breast cancer, and may be candidates. This study showed that aberrant methylation of a panel of four biomarkers occurs in the early stages of breast cancer development. Targeting aberrant methylation may provide an opportunity to modulate cancer risk in the earliest stages of cancer development, at the transformation towards atypia. Striking is the big divergence in methylation levels in tissues of the same lesion type. Whether aberrant methylation in premalignant breast lesions infers a greater risk for disease progression and, eventually, the development of invasive disease, is a question that merits further research in a larger well clinically annotated cohort of patients.

\section{ACKNOWLEDGEMENTS}

This study was supported by funding from Susan G. Komen Breast Cancer Foundation Grant\# BCTR0707528 (DSBH), the Leslie and Susan Gonda (Goldschmied) Foundation (Los Angeles, CA, USA) (DSBH), Associates of Breast and Prostate Cancer Studies (Los Angeles, CA, USA) (DSBH), and Fashion Footwear Association of New York (DSBH), Ruth and Martin H. Weil Fund (DSBH). We thank the staff at the Department of Molecular Oncology, JWCI, for technical support.

\section{REFERENCES}

Agathanggelou A, Cooper WN, Latif F (2005) Role of the Ras-association domain family 1 tumor suppressor gene in human cancers. Cancer Res 65(9): 3497-3508.

Allred DC, Anderson SJ, Paik S, Wickerham DL, Nagtegaal ID, Swain SM, Mamounas EP, Julian TB, Geyer Jr CE, Costantino JP, Land SR, Wolmark $\mathrm{N}$ (2012) Adjuvant tamoxifen reduces subsequent breast cancer in women with estrogen receptor-positive ductal carcinoma in situ: a study based on NSABP protocol B-24. J Clin Oncol 30(12): 1268-1273.

Allred DC, Carlson RW, Berry DA, Burstein HJ, Edge SB, Goldstein LJ, Gown A, Hammond ME, Iglehart JD, Moench S, Pierce LJ, Ravdin P, Schnitt SJ, Wolff AC (2009) NCCN task force report: estrogen receptor and progesterone receptor testing in breast cancer by immunohistochemistry. $J$ Natl Compr Canc Netw 7 (Suppl): 6S1-S21, quiz S22-S23.

Allred DC, Mohsin SK (2000) Biological features of premalignant disease in the human breast. J Mammary Gland Biol Neoplasia 5(4): 351-364.

Bastogne T, Samson A, Vallois P, Wantz-Mezieres S, Pinel S, Bechet D, Barberi-Heyob M (2010) Phenomenological modeling of tumor diameter growth based on a mixed effects model. J Theor Biol 262(3): 544-552.

Beitler PJ, Landis JR (1985) A mixed-effects model for categorical data. Biometrics 41(4): 991-1000.

Buerger H, Otterbach F, Simon R, Poremba C, Diallo R, Decker T, Riethdorf L, Brinkschmidt C, Dockhorn-Dworniczak B, Boecker W (1999) Comparative genomic hybridization of ductal carcinoma in situ of the breast-evidence of multiple genetic pathways. J Pathol 187(4): 396-402.

Burstein HJ, Polyak K, Wong JS, Lester SC, Kaelin CM (2004) Ductal carcinoma in situ of the breast. N Engl J Med 350(14): 1430-1441.

Crawford YG, Gauthier ML, Joubel A, Mantei K, Kozakiewicz K, Afshari CA, Tlsty TD (2004) Histologically normal human mammary epithelia with silenced p16(INK4a) overexpress COX-2, promoting a premalignant program. Cancer Cell 5(3): 263-273.

de Maat MF, Umetani N, Sunami E, Turner RR, Hoon DS (2007) Assessment of methylation events during colorectal tumor progression by absolute quantitative analysis of methylated alleles. Mol Cancer Res 5(5): 461-471.

Degnim AC, Visscher DW, Berman HK, Frost MH, Sellers TA, Vierkant RA, Maloney SD, Pankratz VS, de Groen PC, Lingle WL, Ghosh K, Penheiter L, Tlsty T, Melton 3rd LJ, Reynolds CA, Hartmann LC (2007) Stratification of breast cancer risk in women with atypia: a Mayo cohort study. J Clin Oncol 25(19): 2671-2677.

Dietrich D, Lesche R, Tetzner R, Krispin M, Dietrich J, Haedicke W, Schuster M, Kristiansen G (2009) Analysis of DNA methylation of multiple genes in microdissected cells from formalin-fixed and paraffin-embedded tissues. J Histochem Cytochem 57(5): 477-489.

Dumont N, Crawford YG, Sigaroudinia M, Nagrani SS, Wilson MB, Buehring GC, Turashvili G, Aparicio S, Gauthier ML, Fordyce CA, McDermott KM, Tlsty TD (2009) Human mammary cancer progression model recapitulates methylation events associated with breast premalignancy. Breast Cancer Res 11(6): R87. 
Dupont WD, Page DL (1985) Risk factors for breast cancer in women with proliferative breast disease. $N$ Engl J Med 312(3): 146-151.

Dupont WD, Parl FF, Hartmann WH, Brinton LA, Winfield AC, Worrell JA, Schuyler PA, Plummer WD (1993) Breast cancer risk associated with proliferative breast disease and atypical hyperplasia. Cancer 71(4): 1258-1265.

Ernster VL, Barclay J, Kerlikowske K, Grady D, Henderson C (1996) Incidence of and treatment for ductal carcinoma in situ of the breast. JAMA 275(12): 913-918.

Esteller M (2008) Epigenetics in cancer. N Engl J Med 358(11): 1148-1159.

Foster SA, Wong DJ, Barrett MT, Galloway DA (1998) Inactivation of p16 in human mammary epithelial cells by $\mathrm{CpG}$ island methylation. Mol Cell Biol 18(4): 1793-1801.

Hartmann LC, Sellers TA, Frost MH, Lingle WL, Degnim AC, Ghosh K, Vierkant RA, Maloney SD, Pankratz VS, Hillman DW, Suman VJ, Johnson J, Blake C, Tlsty T, Vachon CM, Melton 3rd LJ, Visscher DW (2005) Benign breast disease and the risk of breast cancer. N Engl J Med 353(3): 229-237.

Hoque MO, Prencipe M, Poeta ML, Barbano R, Valori VM, Copetti M, Gallo AP, Brait M, Maiello E, Apicella A, Rossiello R, Zito F, Stefania T, Paradiso A, Carella M, Dallapiccola B, Murgo R, Carosi I, Bisceglia M, Fazio VM, Sidransky D, Parrella P (2009) Changes in CpG islands promoter methylation patterns during ductal breast carcinoma progression. Cancer Epidemiol Biomarkers Prev 18(10): 2694-2700.

Jeffrey SS, Pollack JR (2003) The diagnosis and management of pre-invasive breast disease: promise of new technologies in understanding pre-invasive breast lesions. Breast Cancer Res 5(6): 320-328.

Jemal A, Siegel R, Ward E, Hao Y, Xu J, Murray T, Thun MJ (2008) Cancer statistics, 2008. CA Cancer J Clin 58(2): 71-96.

Jensen HM, Rice JR, Wellings SR (1976) Preneoplastic lesions in the human breast. Science 191(4224): 295-297.

Kerlikowske K, Molinaro AM, Gauthier ML, Berman HK, Waldman F, Bennington J, Sanchez H, Jimenez C, Stewart K, Chew K, Ljung BM, Tlsty TD (2010) Biomarker expression and risk of subsequent tumors after initial ductal carcinoma in situ diagnosis. J Natl Cancer Inst 102(9): 627-637.

Lo PK, Sukumar S (2008) Epigenomics and breast cancer. Pharmacogenomics 9(12): 1879-1902.

Ma XJ, Salunga R, Tuggle JT, Gaudet J, Enright E, McQuary P, Payette T, Pistone M, Stecker K, Zhang BM, Zhou YX, Varnholt H, Smith B, Gadd M, Chatfield E, Kessler J, Baer TM, Erlander MG, Sgroi DC (2003) Gene expression profiles of human breast cancer progression. Proc Natl Acad Sci USA 100(10): 5974-5979.

Meijnen P, Peterse JL, Antonini N, Rutgers EJ, van de Vijver MJ (2008) Immunohistochemical categorisation of ductal carcinoma in situ of the breast. Br J Cancer 98(1): 137-142.

Moelans CB, Verschuur-Maes AH, van Diest PJ (2011) Frequent promoter hypermethylation of BRCA2, CDH13, MSH6, PAX5, PAX6 and WT1 in ductal carcinoma in situ and invasive breast cancer. J Pathol 225(2): 222-231.

Muggerud AA, Ronneberg JA, Warnberg F, Botling J, Busato F, Jovanovic J, Solvang H, Bukholm I, Borresen-Dale AL, Kristensen VN, Sorlie T, Tost J (2010) Frequent aberrant DNA methylation of ABCB1, FOXC1, PPP2R2B and PTEN in ductal carcinoma in situ and early invasive breast cancer. Breast Cancer Res 12(1): R3.

Murphy WA, DeSchryver-Kecskemeti K (1978) Isolated clustered microcalcifications in the breast: radiologic-pathologic correlation. Radiology 127(2): 335-341.

O’Connell P, Pekkel V, Fuqua SA, Osborne CK, Clark GM, Allred DC (1998) Analysis of loss of heterozygosity in 399 premalignant breast lesions at 15 genetic loci. J Natl Cancer Inst 90(9): 697-703.
Page DL, Dupont WD, Rogers LW, Jensen RA, Schuyler PA (1995) Continued local recurrence of carcinoma 15-25 years after a diagnosis of low grade ductal carcinoma in situ of the breast treated only by biopsy. Cancer 76(7): 1197-1200.

Page DL, Dupont WD, Rogers LW, Rados MS (1985) Atypical hyperplastic lesions of the female breast. A long-term follow-up study. Cancer 55(11): 2698-2708.

Rakovitch E, Nofech-Mozes S, Hanna W, Narod S, Thiruchelvam D, Saskin R, Spayne J, Taylor C, Paszat L (2012) HER2/neu and Ki-67 expression predict non-invasive recurrence following breast-conserving therapy for ductal carcinoma in situ. Br J Cancer 106(6): 1160-1165.

Roll JD, Rivenbark AG, Jones WD, Coleman WB (2008) DNMT3b overexpression contributes to a hypermethylator phenotype in human breast cancer cell lines. Mol Cancer 7: 15.

Roses RE, Paulson EC, Sharma A, Schueller JE, Nisenbaum H, Weinstein S, Fox KR, Zhang PJ, Czerniecki BJ (2009) HER-2/neu overexpression as a predictor for the transition from in situ to invasive breast cancer. Cancer Epidemiol Biomarkers Prev 18(5): 1386-1389.

Roy A (2009) An application of linear mixed effects model to assess the agreement between two methods with replicated observations. J Biopharm Stat 19(1): 150-173.

Shinozaki M, Hoon DS, Giuliano AE, Hansen NM, Wang HJ, Turner R, Taback B (2005) Distinct hypermethylation profile of primary breast cancer is associated with sentinel lymph node metastasis. Clin Cancer Res 11(6): 2156-2162.

Sirchia SM, Ferguson AT, Sironi E, Subramanyan S, Orlandi R, Sukumar S, Sacchi N (2000) Evidence of epigenetic changes affecting the chromatin state of the retinoic acid receptor beta2 promoter in breast cancer cells. Oncogene 19(12): 1556-1563.

Sunami E, de Maat EFG, Vu A, Turner RR, Hoon DSB (2011) LINE-1 hypomethylation during primary colon cancer progression. PLOS ONE 6: e18884.

Tanemura A, Terando AM, Sim MS, van Hoesel AQ, de Maat MF, Morton DL, Hoon DS (2009) CpG island methylator phenotype predicts progression of malignant melanoma. Clin Cancer Res 15(5): 1801-1807.

Toyota M, Ahuja N, Ohe-Toyota M, Herman JG, Baylin SB, Issa JP (1999) CpG island methylator phenotype in colorectal cancer. Proc Natl Acad Sci USA 96(15): 8681-8686.

Van der Auwera I, Bovie C, Svensson C, Trinh XB, Limame R, van Dam P, van Laere SJ, van Marck EA, Dirix LY, Vermeulen PB (2010) Quantitative methylation profiling in tumor and matched morphologically normal tissues from breast cancer patients. BMC Cancer 10: 97.

van Hoesel AQ, van de Velde CJ, Kuppen PJ, Putter H, de Kruijf EM, van Nes JG, Giuliano AE, Hoon DS (2012) Primary tumor classification according to methylation pattern is prognostic in patients with early stage ER-negative breast cancer. Breast Cancer Res Treat 131(3): 859-869.

Wellings SR, Jensen HM (1973) On the origin and progression of ductal carcinoma in the human breast. J Natl Cancer Inst 50(5): 1111-1118.

Wellings SR, Jensen HM, Marcum RG (1975) An atlas of subgross pathology of the human breast with special reference to possible precancerous lesions. J Natl Cancer Inst 55(2): 231-273.

This work is published under the standard license to publish agreement. After 12 months the work will become freely available and the license terms will switch to a Creative Commons AttributionNonCommercial-Share Alike 3.0 Unported License. 